\title{
SUBJETIVIDADES JUVENILES EN TIEMPOS DE PANDEMIA. LA EXTRAÑA CONDICIÓN DE SER «MECHÓN» NO PRESENCIAL ${ }^{1}$
}

\author{
MANUEl ANTONIO BAEZA ${ }^{2}$ \\ ANDREA ARAVENA ${ }^{3}$
}

\begin{abstract}
RESUMEN
Estudiantes de primer año de la enseñanza superior universitaria exponen, en el marco de una investigación de tipo cualitativo, realizada en 2020, sus frustraciones y también sus esperanzas en medio de una devastadora pandemia y de una profunda y multifacética crisis de las confianzas sociales. Se constata, en estas condiciones muy especiales, una heterogeneidad de visiones y posicionamientos que germinan en la subjetividad de jóvenes personas que, sin embargo, y de manera insólita, no han puesto todavía un solo pie en un aula universitaria. Entre repliegues individualistas y vocaciones sociales se dibujan aspiraciones y expectativas que, en las actuales condiciones, no se disocian fácilmente de poderosas e inéditas incertidumbres.
\end{abstract}

PALABRAS CLAVES: INTERSUBJETIVIDAD, ASPIRACIONES, EXPECTATIVAS, PANDEMIA

\footnotetext{
${ }^{1}$ Proyecto PI/06 UCO 1895 Nuevas subjetividades e imaginarios sociales juveniles de la educación superior en estudiantes de primer año de la Universidad de Concepción y el Instituto Virginio Gómez.

${ }^{2}$ Doctor en Sociología, Universidad de La Sorbonne Nouvelle, Paris III. Académico del Departamento de Sociología, Facultad de Ciencias Sociales, Universidad de Concepción, Chile. Correo electrónico: mbaeza@udec.cl

${ }^{3}$ Doctora en Antropología Social y Etnología, École des Hautes Études en Sciences Sociales, Paris. Académica Facultad de Ciencias Sociales, Universidad de Concepción, Chile. Correo electrónico: andrea.aravena@udec.cl
} 


\title{
SUBJETIVIDADES JUVENIS EM TEMPOS DE PANDEMIA. A ESTRANHA CONDIÇÃO DE SER UM CALOURO NÃO PRESENCIAL
}

\begin{abstract}
RESUMO
No contexto de uma pesquisa qualitativa realizada em 2020, estudantes do primeiro ano do ensino superior descrevem suas frustrações e suas esperanças no meio de uma pandemia devastadora e de uma profunda e multifacetada crise das confianças sociais. Nestas condições muito especiais, pode-se observar uma heterogeneidade de visões e posicionamentos que germinam na subjetividade de jovens pessoas que, porém, e excepcionalmente, ainda não estiveram em uma sala de aula universitária. Entre os recolhimentos individualista e as vocações sociais, são traçadas aspirações e expectativas que, nas condições atuais, não são facilmente dissociadas de incertezas poderosas e sem precedentes.
\end{abstract}

PALAVRAS-CHAVE: INTERSUBJETIVIDADE, ASPIRAÇÕES, EXPECTATIVAS, PANDEMIA.

\section{YOUTH SUBJECTIVITIES IN PANDEMIC TIMES. THE STRANGE CONDITION OF BEING A REMOTE FRESHMAN}

\begin{abstract}
First-year higher education students show their frustrations and hopes during a devastating pandemic within the framework of a qualitative research carried out in 2020. Under these very special conditions, it is evident the presence of a heterogeneity of views and positions which arise in the subjectivity of young people who unbelievably have never set a foot in an on-site university classroom. Between individualistic withdrawals and social vocations, they draw aspirations and expectations that, under the current conditions, cannot be easily dissociated from powerful and unprecedented uncertainties.
\end{abstract}

KEYWORDS: INTERSUBJECTIVITY, ASPIRATIONS, EXPECTATIONS, PANDEMIC. 


\section{INTRODUCCIÓN}

Atravesamos tiempos difíciles a nivel global, casi sin tener espacios físicos y sociales de repliegue defensivo frente a una amenaza microscópica pero letal, la de un virus a escala pandémica. Ni siquiera el espacio doméstico familiar reúne las condiciones de asepsia para considerarlo seguro, especialmente por el carácter asintomático de la enfermedad. Desde hace un par de años, constatamos que la velocidad de expansión del coronavirus ha sido extremadamente alta y la escala de dicha expansión es hoy universal, es decir, sin áreas geográficas a resguardo del contagio. Esto último ocurre porque en la «aldea-mundo», todo viaja muy rápido, sin dejar espacio por recorrer o descubrir. Resulta muy expedito constatar que los estragos y efectos en curso de la pandemia por Covid19 son devastadores, no solamente en el plano de los respectivos sistemas nacionales de salud pública —entiéndase tanto infraestructura hospitalaria y disponibilidad de camas, como modelo organizacional, cantidad de personal calificado, estrategias, planificación y protocolos de contención y profilaxis, producción y disponibilidad de oxígeno e insumos diversos, etc.- , teniendo como corolario fatal los costos inestimables que representa la pérdida de vidas humanas.

En estrecho correlato, se advierten efectos aún incalculables, también, en el campo de la economía, sumida en una crisis sin precedentes en los tiempos modernos, con los enormes impactos sociales que dicha crisis acarrea en cada rincón del planeta, con un incremento sustantivo de la pobreza, consecutivo al desplome del mercado de trabajo que, en el caso chileno, comprende una desaparición en un par de años de dos millones de puestos de trabajo. A escala mundial, según el FMI, en 2024 el producto global será -3\% del volumen previsto antes de la pandemia, lo cual pone de manifiesto pérdidas importantes a mediano plazo, con consecuencias fáciles de deducir en materia de cesantía y miseria. 
Efectos igualmente nocivos en el campo de la educación, con procesos acelerados de desescolarización, de nuevas inequidades debidas a la modalidad de educación a distancia, sobre todo en áreas rurales de baja conectividad y en sectores sociales vulnerables y de recursos escasos. Existen, por este tipo de consideraciones, sospechas acerca de la efectividad de la educación remota, llegando incluso algunos especialistas a hablar de los resultados de esta experiencia como los de un «apagón pedagógico», ya en curso desde antes de la pandemia por la introducción abrupta de la virtualidad (Bonilla-Molina y Ortega, 2021).

No podemos olvidar el hecho de que la pandemia llegó a Chile inmediatamente después del llamado «estallido social» de octubre de 2019, una importante manifestación de la desconfianza y el descontento social imperantes en un país que daba muestras explícitas de profundos cambios en las subjetividades sociales (Aravena y Baeza, 2015; Baeza, 2020). La demanda cualitativa de mayor dignidad y respeto reemplazaba por primera vez la demanda cuantitativa tradicional por mejores salarios. Sin duda, desde un punto de vista aspiracional, los jóvenes habían visto afectados sus proyectos en este inicio de la década, alimentando así importantes cuotas de desaliento (Canales, Guajardo y Orellana, 2020).

Por otra parte, en tiempos de pandemia es imposible obviar los alcances en materia de deterioro de la salud mental en estudiantes (Asún, Palma, Aceituno y Duarte, 2021) y, en general, se vislumbra en personas que deben observar largos períodos de confinamiento, sedentarismo forzado, distanciamiento físico con seres queridos, incertidumbre frente a potenciales escenarios postpandemia, etc., secuelas más tardías, aunque no menos significativas.

Son innumerables las prácticas sociales que resultarán irrepetibles en sus modalidades precedentes por el simple hecho de una cohabitación con un nuevo tipo de virus, agresivo y mortífero. Se puede prever una fase prolongada de 
adaptación o, en su defecto, de inadaptación —individual y colectiva - a la situación presente, así como también un conjunto de mutaciones culturales que irán en el sentido de una «nueva normalidad» social. Tal adaptación ya ha comenzado, contra todo escepticismo, voluntad de cuestionamiento y consideraciones ideológicas, porque lo que prima es, de seguro, el instinto de supervivencia.

En este contexto nos proponemos observar las subjetividades juveniles estudiantiles, con sus lecturas colmadas de perplejidad y de desconfianza, pero también de esperanzas y anhelos que bien vale la pena identificar para los efectos de otorgar inteligibilidad a lo que serán de aquí en adelante las sociedades humanas del siglo XXI, en particular la chilena. Lecturas que, por lo demás, pasan por cultivar diferencias intergeneracionales para afirmar la condición de ser «joven», en tanto sujeto y actor de la sociedad en la que viven (Zarzuri y Ganter, 2005). Cabe, sin embargo, subrayar que el tema de «lo juvenil» debe ser debidamente esclarecido en su uso en estas páginas, considerando en primer lugar el adultocentrismo reinante (Duarte, 1994) en los códigos sociales y también en las taxonomías en curso en nuestra sociedad, lo que finalmente no hace más que naturalizar una noción extremadamente vaga como es «la juventud», «los jóvenes», «lo juvenil» (Duarte, 2012). Entonces, nos limitaremos exclusivamente a un empleo instrumental de lo que entendemos por subjetividades juveniles en un sentido restringido: construcciones de significaciones socialmente compartidas por personas al ingresar a la educación superior. Esto permite hacer prevalecer la visualización de todo un tramado de relaciones y de dinámicas de posiciones sociales específicas (Bourdieu, 1990), soslayando el aspecto etario como si este fuere el factor problemático, decisivo y exclusivo.

Esta mirada es, en sentido estricto, parcial, exploratoria. Se realiza en un momento específico con jóvenes que cursan primer año de formación universitaria y también técnica profesional en dos planteles educacionales importantes de la ciudad de Concepción (Chile). Con prolongadas cuarentenas, 
uno de los temas álgidos desde hace más de un año es el estado de la salud mental de la población y, al hablar de jóvenes, el diagnóstico general es inquietante. Un estudio en Perú, por ejemplo, mediante el análisis de las percepciones de 74 estudiantes de la Pontificia Universidad Católica del Perú, ha revelado que los estudiantes que no tenían adecuados recursos tecnológicos frente a quienes sí los tenían, las clases no presenciales generaban estrés, sobrecarga académica, frustración y deserción universitaria (Lovón y Cisneros, 2020). En Chile, donde ha habido igualmente una importante expansión y masificación de la educación superior a los primeros quintiles socioeconómicos y a estudiantes de menor rendimiento en la enseñanza media, se ha configurado un tipo de estudiante con tasas significativas de trastornos adaptativos, trastornos del ánimo, trastornos de ansiedad, desórdenes de personalidad y antecedentes de conducta suicida (Micin y Bagladi, 2011). Igualmente, se ha señalado que el cansancio, el miedo, la tristeza y la angustia son sentimientos que dominarían la experiencia de las generaciones jóvenes e intermedias, y se establece que el factor generacional, el género y el estrato social de pertenencia serían variables importantes a la hora de definir estos problemas en la población que cursa estudios superiores (Universidad de Chile, 2021). En este contexto, indagar sobre subjetividades juveniles en medio de la tormenta es un desafío considerable. El trabajo investigativo tiene lugar entonces en condiciones excepcionalísimas, con cohortes que, habiendo ingresado a la educación superior, no han conocido las clases presenciales, no han vivido en carne propia los ritos profanos de iniciación que se asocian a la condición de «mechones», no han podido ni siquiera conocerse con sus nuevos compañeros/as, condición esta última que ha sido ajena a la más mínima posibilidad de cercanía física. 


\section{ELEMENTOS CONSTITUTIVOS DE LA SUBJETIVIDAD}

Nuestro objeto de estudio requiere un par de aclaraciones previas al análisis de contenidos correspondiente a voces propias de un segmento específico de población como es el de jóvenes. El primer tema es de carácter conceptual y puede dar origen a varias preguntas casi de manera espontánea, formando incluso una secuencia para nada exhaustiva: ¿qué es la subjetividad?, ¿qué importancia tiene en nuestra vida cotidiana?, ¿qué importancia tiene intentar conocer lo que hemos denominado subjetividades juveniles?

Intentemos responder en orden estas mismas preguntas. En primer lugar, para elucidar el concepto de subjetividad podemos decir de entrada que tras ese concepto se esconde toda una larga historia de la especie humana, no exenta de ciertas opacidades que han sido analizadas desde distintos abordajes (véase, por ejemplo: Corona, 2009) y que nosotros mismos hemos tratado en otra oportunidad (Baeza, 2015). De manera extremadamente sucinta podemos decir que, en una relación de causa a efecto, es probablemente la mayor de las paradojas de la existencia de los seres humanos el haber alcanzado una sofisticación admirable del cerebro, a través de un proceso de desarrollo experiencial que recorrió miles de años y que, como consecuencia indeseada, produjo simultáneamente una percepción de extrañamiento con respecto a la naturaleza y al entorno en general, es decir, un distanciamiento cognitivo que el instinto, atrofiado y limitado a la sola cuestión de la supervivencia, no puede compensar ya de modo alguno. En tales condiciones, para un individuo, lo que denominamos mundo en sentido amplio, en términos de su comprensión, es algo que requiere ser mediado, intervenido mentalmente: esa actividad psíquica relacional es, en definitiva, aquello que denominamos subjetividad, o sea, nuestra capacidad de significar todo cuanto nos rodea (Baeza, 2015).

Ahora bien, y tal como lo expresara en su momento Schutz, la experiencia del mundo de la vida social no es lo propio de un solipsismo vulgar, es decir, no 
es la de individuos que centran su conciencia exclusivamente en la aventura experiencial del Yo, sino una auténtica e insoslayable experiencia colectiva, propia de un mundo social, razón por la cual y a través de la interacción y de la comunicación circulan contenidos de «mundo significado» que finalmente se pueden compartir socialmente, abriendo paso a la cooperación y la reciprocidad necesarias en la aventura de la vida social. Entonces, para esos efectos, y como la subjetividad individual no basta, debemos instalar el concepto de intersubjetividad, asumiendo por lo tanto que las subjetividades —así, dichas en plural- han de ser entendidas en el texto como conjuntos gruesos de significación compartida, en circulación permanente, a partir de la experiencia del mundo de la vida social, en este caso que aquí nos retiene, por personas jóvenes. Es de manera intersubjetiva y en la interacción social, vale decir, con la participación activa de Alter que los procesos de aprendizaje tienen finalmente lugar (Torres, 2019) y se comienzan a formular aspiraciones no menos marcadas socialmente (Sepúlveda y Valdebenito, 2014).

La segunda pregunta que formulábamos más arriba se desprende lógicamente de los contenidos de la respuesta anterior: intentar saber si en medio de un escenario desolador las subjetividades juveniles pueden o no construir ciertos horizontes positivos. Con tal propósito, señalemos que uno de los caminos más expeditos para llegar a un nivel importante de profundidad en el conocimiento de las subjetividades humanas es aquel del desciframiento cualitativo de las esperanzas, porque en estas hay una clara reducción de la materialidad presente en la existencia, a la vez que una apertura del pensamiento hacia espacios no delimitados o no confinados. En otras palabras, una idealización sui generis de lo material, por enfrentamiento directo de la sensación de fatalidad. Las esperanzas -0 , en su defecto, las desesperanzas - se construyen en estrecha relación con contenidos eventuales de una porción de tiempo que todavía no es, a saber, la dimensión referida al tiempo futuro. Nos proponemos ver en páginas siguientes que las distintas subjetividades juveniles 
significan el futuro de manera no uniforme, ni mucho menos. Finalmente, las esperanzas difieren cualitativamente de las utopías en tanto las primeras no radican su atención en la cuestión de un lugar o espacio ( $\tau$ ó $\pi \circ \varsigma$ ), porque las esperanzas -que tienen parentesco tanto con aspiraciones como con expectativas - se construyen con mayor apego a las oportunidades que puede brindar la realidad, no como construcción de alternativa a lo real y al lugar de ocurrencia, que es lo propio de las utopías en el sentido de Tomás Moro.

Pone todo esto en juego a las ecuaciones personales respectivas, con significaciones anteriores de experiencias ya recorridas —individual y colectivamente - y que han sido conservadas en la memoria, con creencias y esquemas de valores abstractos de distinto origen, con capacidad lógico-racional de enfrentar problemas y situaciones nuevos, con estados psicológicos positivos o negativos y, sobre todo, con la activación de todo el potencial creativo de la imaginación (Baeza, 2003). Al hablar entonces más arriba de contexto en sentido amplio, no podemos concluir en una lectura única del mismo; cada subjetividad, cada ecuación personal, trabaja en tal dirección, pero no concluye su trabajo de manera uniforme, ni mucho menos. No obstante, las posibilidades de conexión y de correspondencia entre tales lecturas de situaciones, de problemas, de momentos históricos, etc., están siempre abiertas por la vía de la intersubjetividad, la cual opera en términos simbólicos y analógicos como mecanismo social de legitimación de significaciones válidas para la vida en sociedad. Dicho sea de paso, se diluye así la pretensión de operar desde una subjetividad prescindente de lo social que, desde luego, la condiciona y hasta le otorga un formato «socialmente aceptable».

Tratándose de personas jóvenes, enfrentando así la tercera pregunta formulada más arriba, la hipótesis de la dinámica de una esperanza —o su negación de ella- que al irrumpir se revela como algo más importante que en adultos mayores, esto es algo perfectamente plausible. El momento del ingreso a la educación superior autoriza a suponer que precisamente el tema de la 
esperanza se refuerza al ritmo de nuevas expectativas y aspiraciones propias de personas jóvenes. En ellos/ellas, la probabilidad es mayor de desarrollar imaginarios sociales de la vida humana, entendiendo a esta como horizontes o, por el contrario, como negación absoluta de horizontes, cuestión que tiende a disminuir gradualmente al avanzar la edad. Ahora bien, si se considera que las esperanzas se consolidan más bien en etapas, en temporalidades exentas de sobresaltos, o sea a través de continuidades y no de rupturas, una nueva pregunta central es obvia: ¿cuánto puede afectar un fenómeno tan gigantesco e intempestivo como la pandemia a las esperanzas juveniles?

\section{Algunas CUESTIONES METOdOlÓgICAS de LA INVESTIGACIÓN}

No es muy frecuente observar el hecho de que los científicos sociales transparenten en sus textos sus propias formas más prácticas de operar en materia de investigación y, a menudo, una exigencia al respecto a la hora de publicar es simplemente inexistente. Sin embargo, dado el contexto complejo ocasionado por la pandemia y, en particular, el impacto de todo esto en el trabajo en terreno, se agudiza la necesidad de tomar posición y decisiones importantes que consideramos oportuno poner en superficie. En esta oportunidad y con ese trasfondo se llevó a cabo un diseño especial, enfatizando el uso más avanzado del computador (Flick, 2012) en diversas fases del trabajo científico. Es así como en esta investigación se realizaron 58 entrevistas semiestructuradas online, conforme a pautas elaboradas por un equipo que comprendía un trío de investigadores/as (una antropóloga, un sociólogo y una educadora) más un pequeño grupo de jóvenes profesionales que, con su activa participación, permitieron otorgar una sensibilidad aún más actualizada y penetrante a la observación, es decir, una condición necesaria para una adecuada comprensión de lo que son, en sentido fuerte de la palabra, nuevas subjetividades juveniles. 
Es importante explicitar la cuestión de los criterios muestrales en orden a dos principios: el de semialeatoriedad de la muestra y el de distribución equitativa por género. Por ende, las series de entrevistas fueron debidamente organizadas y luego realizadas durante el primer año de pandemia, en dos instituciones de enseñanza superior de la ciudad de Concepción (Universidad de Concepción e Instituto Profesional Virginio Gómez), incluyendo estudiantes de primer año de 2020 de distintas carreras técnicas y universitarias de manera aleatoria dirigida (es decir, haciendo intervenir la aleatoriedad dentro de zonas de formación preestablecidas que permitiesen tener representatividad de todos los campos de formación), lo cual nos permitió establecer, finalmente, mediante un análisis hermenéutico, una tipología que por razones de espacio restringiremos en estas páginas a estudiantes universitarios, vale decir, dejando pendiente lo que corresponde tanto a estudiantes de carreras técnicas en específico como a un análisis comparado de ambos tipos de estudiantes. Por su parte, el criterio de distribución equitativa por género se aplicó por decisión discriminatoria positiva del equipo de investigación.

De manera entonces que, frente a la imposibilidad de realizar entrevistas presenciales, se recurrió a las plataformas Zoom y Teams, lo cual tuvo como resultado la producción de corpus de discurso de una duración promedio de cuarenta minutos. Los materiales recogidos fueron sistematizados en NVivo $11 \mathrm{y}$ clasificados en una malla temática, permitiendo así los análisis correspondientes. En las citaciones textuales que el lector encontrará en estas páginas se conservó la nomenclatura de identificación de las entrevistas, incorporando así algunos elementos relevantes de identificación, tales como tipo de establecimiento de enseñanza superior — técnica o universitaria-, género, carrera y tipo de financiación de estudios. Advertimos en todo caso al lector/a la restricción que hacemos en el tratamiento de datos en este artículo a los/las estudiantes universitarios/as, por una cuestión de extensión del artículo, lo cual no altera, sino a través de ciertos énfasis diferenciados, los resultados de la investigación 
que sirve de respaldo. De modo entonces que, tal como podrá verse en el texto a través de fragmentos de entrevistas seleccionados como ejemplos, la nomenclatura empleada es la siguiente ${ }^{4}$ :

\begin{tabular}{|l|l|}
\hline U / I & $\begin{array}{l}\text { Estudiante universitario / } \\
\text { Estudiante de instituto } \\
\text { técnico-profesional }\end{array}$ \\
\hline $1 / 2$ & Varón / Mujer \\
\hline AGRONO & Carrera \\
\hline 1 & $\begin{array}{l}\text { Tipo de institución de } \\
\text { enseñanza media en último } \\
\text { año (4º medio): } \\
1=\text { municipal; } 2= \\
\text { particular subvencionado; } 3 \\
=\text { particular pagado; } 4= \\
\text { otro. }\end{array}$ \\
\hline TJA / NTJA & Trabaja / No trabaja \\
\hline 15 & $\begin{array}{l}\text { Número correlativo general } \\
\text { de entrevista }\end{array}$ \\
\hline
\end{tabular}

\section{ESQUEMAS BáSICOS DE CLASIFICACIÓN}

El recurso a la hermenéutica permite múltiples idas y vueltas a la producción discursiva, en diálogo constante con el contexto de elaboración de dichos discursos. Tales movimientos se realizan de manera centrípeta, en primer lugar, intentando ir hacia los nudos centrales en la estructuración subjetiva de aquellos, para luego expandir de manera centrífuga el análisis hacia zonas discursivas que se revelan como partes argumentativas de un modo u otro tributarias o dependientes de los núcleos principales. Entonces, desde un punto de vista propiamente analítico de los respectivos corpus de las entrevistas, se dibuja claramente y de manera temprana en la superficie una distinción semántica entre

\footnotetext{
${ }^{4}$ Este tipo de nomenclaturas ya ha sido utilizado por el mismo equipo de investigación en varios proyectos Fondecyt, por el hecho de permitir una fácil identificación de personas entrevistadas, manteniendo el nivel de confidencialidad en el manejo ético de identidades en los análisis y clasificaciones correspondientes.
} 
dos tipos diferenciadores en la construcción intersubjetiva de discursos de mayor elaboración. Se trata, para los/as investigadores/as, en el lenguaje del filósofo Castoriadis, de la detección de dos grandes núcleos magmáticos psíquicos de los que se desprenden determinados rasgos orientadores centrales de sentido subjetivo, o lo que el autor mencionado denominaría imaginarios radicales (Castoriadis, 2007), que organizan la totalidad argumentativa, poblándola con elementos subordinados que este autor conceptualizó como imaginarios periféricos o secundarios. En sentido castoriadino, en una lógica que él llama lógica ensídica (o conjuntista-identitaria), lo subjetivo reúne, clasifica, ordena, jerarquiza, etc., todo lo cual permite ampliar y extender a totalizaciones de sentido el ámbito de las significaciones.

Es entonces en conformidad a lo empíricamente observado que una tipología resultante se compone en suma de dos perfiles gruesos, de tipos subordinados a dichos perfiles, aunque más específicos $\mathrm{y}$, por último, de subtipos también debidamente caracterizados a través del análisis de sentido subjetivo, configurando una estructura arborescente que podemos esquematizar de la manera siguiente (ver cuadro 1):

CUADRO N¹. FUENTE: ELABORACIÓN PROPIA EN PROYECTO PI 06-UCO 1895.

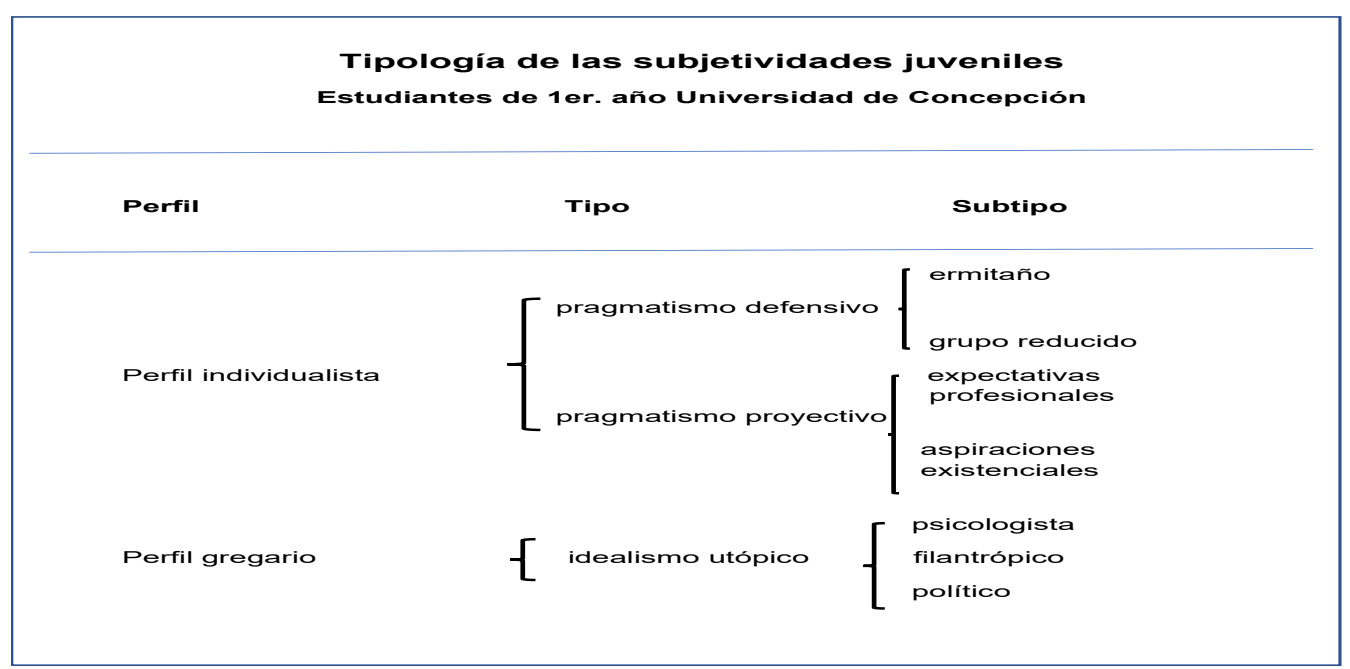


Se aprecian con toda nitidez, y a la base del análisis en profundidad, dos grandes perfiles que hemos denominado para fines meramente instrumentales: subjetividad individualista, con abierta centralidad del Yo, como lo veremos más adelante, y subjetividad gregaria, con importancia clara de lo social en la percepción/comprensión de la existencia. Ellos son muy diferentes entre sí, pero con rasgos adicionales importantes que les vuelven a fraccionar al interior de cada perfil inicial. Esto redunda, en el caso del perfil individualista, en la emergencia de dos grandes tipos que, a su vez, se fraccionan en dos subtipos, tal como se aprecia en el cuadro 1. El perfil gregario, por su parte, deriva en un solo tipo dividido inmediatamente en tres subtipos que expresan con seguridad todo un conjunto de cambios cualitativos muy recientes en la visualización de la sociedad en sentido amplio. Veamos entonces esta tipología con mayor detalle en su caracterización, con el objeto de poder visualizar con mayor nitidez cada uno de esos tipos y subtipos.

\subsection{PeRfil individualista}

Desde comienzos de la Modernidad occidental, la cuestión de la formación de una conciencia individual constituyó probablemente la promesa fundamental, o si se prefiere, la premisa de la libertad más auténtica; esto es algo que Durkheim detectaba en los albores de la sociología y lo atribuyó a la división del trabajo social. La paradoja principal pudo consistir, sin embargo, en que la singularización pondría finalmente a prueba las estructuras societales que vieron nacer a dichos individuos (Martuccelli y De Singly, 2012). Parafraseando a Touraine (2016), diríamos también que la globalización contribuye fuertemente a la disolución del vínculo social, de la noción misma de sociedad, en la medida en que la reivindicación de derechos desde la Revolución francesa en adelante que conduce a la mencionada noción - se vuelve ahora reclamo por el ejercicio efectivo de derechos, sobre todo de carácter individual. En otras palabras, la 
construcción de sujetos individuales se realiza en desmedro de la sociedad que los procreó.

Ahora bien, es necesario también advertir que los procesos de individualización fueron inobjetablemente más lentos y también más tardíos en espacios distantes de Europa y de Norteamérica al no disponer, en vastas áreas geográficas como América Latina, por ejemplo, de la base material para tal desarrollo. Sin embargo, es posible sostener que el proceso de individualización se ha acelerado en Chile en el curso de los últimos cuarenta años (Baeza, 2020), lo cual se refleja en nuevas estructuras de la subjetividad, especialmente en segmentos de población nacidos en el siglo XXI, como bien lo señalan Araujo y Martuccelli (2012). En este sentido, los discursos juveniles se ven aquí sólidamente anclados en la centralidad de un Yo que proclama mayor o menor grado de prescindencia de lo social, reiterando elementos ya detectados en tendencias narcisistas de comienzos de siglo, de manera parecida a cómo lo ha puesto de manifiesto en su momento Maffesoli. El mundo, en sentido amplio, es visto desde un prisma utilitario o, en su defecto, es reducido a una llamativa opacidad que, sin embargo, obedece a dos direccionamientos de sentidos: uno de tipo pragmático defensivo y otro de carácter pragmático proyectivo. Las diferencias cualitativas constatadas entre estos dos subtipos son considerables, tal como puede observarse en el cuadro 2 :

CUADRO N². FUENTE: ELABORACIÓN PROPIA EN PROYECTO PI 06-UCO 1895.

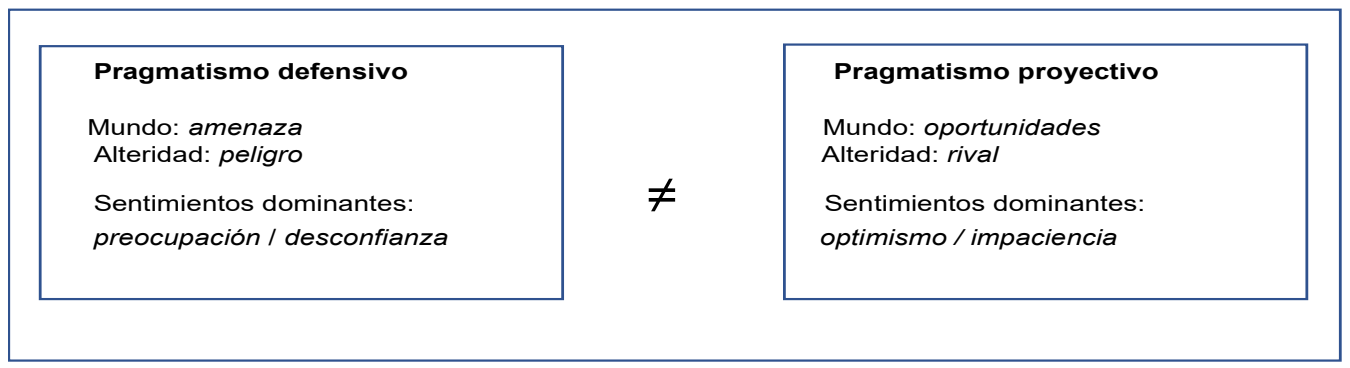


En otras palabras, ambos tipos son caracterizados por nosotros como pragmáticos porque construyen in fine sus acciones sociales subjetivamente mentadas — parafraseando el discurso weberiano — sobre la base de una relación costo-beneficio que fundamenta aquellas en un sentido o en otro; el pragmático defensivo y el pragmático proyectivo no parecen dudar de dichos fundamentos $\mathrm{y}$, con miedo el primero y con fuerte determinación el segundo, orientan sus pasos respectivos hacia objetivos que proclaman tener muy claros. En el lenguaje de Bourdieu, podemos entonces advertir el hecho de que ambos pragmatismos construyen redes relacionales y pretenden acceder a posiciones en conformidad a esos objetivos que sostienen ser muy nítidos en sus contenidos. Defenderse como imperativo absoluto en el primer caso, emprender como prioridad insoslayable en el segundo.

El factor pandemia interviene reforzando poderosamente todo un conjunto de convicciones personales que, en medio del confinamiento, las clases virtuales y el diálogo inexistente con estudiantes coetáneos, crece con la incertidumbre y con la necesidad de toma de decisiones prácticas. Parecen ser tiempos de introspección, o más bien, tiempos de soliloquios reflejados con nitidez en las entrevistas. Veamos a continuación las características de ambos tipos de individualismos.

\subsubsection{Pragmatismo defensivo}

Llama poderosamente la atención el hecho de que en el perfil individualista ese pragmatismo que hemos llamado defensivo hay, en primer lugar, una inclinación temerosa frente a lo social, lugar abstracto per se en donde emerge fuertemente y como consecuencia lógica la incertidumbre, vale decir, una característica difícilmente atenuable en la coyuntura actual. La confianza en formas e instituciones sociales es algo perfectamente ausente en este tipo de postura subjetiva. La idea de mundo es comparable a la de un ambiente hostil, en 
el cual Ego debe mantenerse a distancia de múltiples y permanentes peligros y amenazas; el flagelo del coronavirus no escapa, por cierto, a esa sensación de vivir en un mundo inamistoso y productor de contagios letales. Para este tipo de individualismo, el factor confianza social es un elemento perfectamente ausente, tendencia que una crisis multifacética como la actual no revierte, sino que inclina hacia nuevas formas de desaliento. En este tipo de escenarios, la búsqueda de empatía es un acto a menudo inútil al prevalecer en Alter, a juicio de Ego, una tendencia a las conductas no virtuosas, algo considerado como intrínseco en la mayoría de los individuos, algo no muy lejos de la célebre concepción hobbesiana de una naturaleza humana intrínsecamente perversa. Este tipo de individualismo pragmático defensivo parece incluso promover en Ego la figura de un ser asocial, cuando no directamente la de un ermitaño, tal como lo explicita un entrevistado de la carrera de Agronomía:

De repente, me gustaría tener un bosque y perderme, solo, sin nadie, ser como un ermitaño. Es como un sueño individual. (U1AGRONO1NTJA07)

En este orden de ideaciones, es evidente que la relación subjetiva y de significación con el tiempo es también bastante problemática, porque una de las dimensiones reconocibles de aquel, que no es ni el «pasado» ni el «presente», sino el hasta incluso enigmático tiempo «futuro», se transforma, sin duda, en la dimensión más incontrolable, por sus siempre eventuales e hipotéticos contenidos; en realidad, en un contexto de virtualidad, el tiempo significado como «futuro» es un promotor importante de miedos y de incertidumbres factuales siempre renovados a través de lecturas subjetivas del acontecer en sentido amplio (social, económico, político, etc.). El pragmatismo defensivo resuelve entonces el enigma designificando el «futuro», esto es, suprimiendo cualquier alusión consciente a todo factor potencial de generación de temores:

La verdad es que yo no pienso mucho en el futuro, solo pienso en una cosa, trato de vivir el día a día. (U1AGRONO1NTJA07) 
Sin embargo, el pragmatismo defensivo, aquel que se sostiene a menudo sobre la idea del manejo del «día a día», conoce también una variante a considerar cuando admite, con sentido no menos pragmático, la existencia de un grupo restringido de personas que configuran un entorno inmediato, a menudo la familia. El individualismo no excluye aquí lo que podríamos considerar el plano de las relaciones proxémicas más inmediatas, las solidaridades básicas, a saber, aquellas que están dirigidas al bienestar de los seres queridos:

Primero, titularme, me gustaría viajar, encontrar un trabajo estable y hacer que mi mamá no trabaje más. (U1GEOLOG2NTJA41)

Los objetivos profesionales y personales de esos/esas jóvenes se ajustan a cuestiones relativas a futuro propio, siempre en búsqueda de seguridades ontológicas y, eventualmente, al de personas cercanas que configuran ese entorno restringido - probablemente involuntario - y hacia quienes se orientarían los posibles beneficios, sobre todo económicos, de la formación universitaria pretendida. En otras palabras, la noción de grupo social es reducida a un mínimo de miembros, predominando para ello razones preminentemente afectivas que justifican la posibilidad de extensión de beneficios.

\subsubsection{Pragmatismo proyectivo}

Los pragmatismos tienen que ver, en general, con una adecuación entre medios y fines, dicho a la manera de Weber en su clásica presentación idealtípica de la acción social racional con arreglo a fines. Pues bien, en el caso del pragmatismo proyectivo, tal adecuación subjetiva se observa muy nítidamente. Desde un punto de vista típico ideal, entonces el individuo pragmático arma conjeturas y se mueve con una lógica aparentemente fría y calculadora, que parece reservar sentimientos para círculos sociales estrechos e íntimos. Es también el universo de las expectativas profesionales personales por excelencia, 
más allá de una formación universitaria. Todos estos rasgos son trasladados al discurso, así como lo demuestra esta alumna de Arquitectura:

Mis sueños son tener una familia, tener una pareja, mis hijos, tener una casa, estar bien, cómoda, feliz. Mi sueño es estar bien, plena, feliz. También, mi sueño es viajar, no me veo aquí en el país. Viajar, conocer, buscar y encontrar la ciudad, el lugar donde me sienta como yo, segura, y ahí formar todo. (U2ARQUIT2NTJA13)

Aparece aquí muy claramente explicitado el propósito formativo personal, a saber, y en primer lugar, la obtención de un título universitario con el cual enfrentar la vida adulta, el hecho de obtener un trabajo estable, crear una familia, todo lo cual puede ser entendido como beneficio que se puede extender, por ejemplo, a un grupo familiar estrecho. Si la mirada hacia el futuro es convencional, ella no se limita a menudo a una proyección en el campo formativo elegido; en otras palabras, a las expectativas profesionales se añaden aspiraciones existenciales —familiares clásicas o simplemente lúdicas - en un continuum:

Me gustaría mucho investigar, hacer investigaciones; me gustaría tener mi casa, tener mi familia, tener hijos, me gustan mucho los niños, demasiado. Mi vida profesional, me veo como una gran profesional porque me gusta tanto el tema y no es algo que haga porque me dé plata o porque me vaya bien, simplemente. Sino que lo hago con pasión. Y encuentro que eso es bueno. (U2GEOFIS2NTJA43)

La proyección personal es, en esta caracterización, algo más que un reflejo defensivo. Es más bien entendida como una inversión en y para sí mismo, aunque también pudiendo ser extensiva a seres queridos de un entorno inmediato. Hay en esta modalidad aspectos clásicos de lo que se conoce como una aspiración a lo que entiende como la legitimidad de una progresión en la escala de posiciones sociales, o sea, un anhelo de obtención del reconocimiento y de los beneficios de un sistema de movilidad social ascendente, en un afán que combina también un ideal de felicidad, donde no están ausentes ni la impaciencia por alcanzar esas metas ni tampoco el optimismo basado en la perseverancia y el esfuerzo personal. 
Si bien es cierto la figura de Alter no es explicitada con elocuencia en este tipo de subjetividades, ella aparece, a través de la distancia, como un obstáculo potencial frente a expectativas y aspiraciones personales. Ese Alter queda a veces sugerido a través del personaje de un compañero/a de universidad a quien no se conoce, dadas las condiciones de educación no presencial, pero que tal situación no incomoda mayormente. Por otra parte, y tal como los rasgos anteriormente descritos comienzan a ser esbozados, las ideas de posesión de bienes, de uso de servicios, de goce individual, de realizar experiencias vitales incluso muy distintas de la formación que se empieza a recibir, están presentes en este perfil igualmente. Si la prescindencia de lo social no es absoluta, esta aparece en algunos casos solamente como un problema u obstáculo, en términos relativos, tal como lo pone de manifiesto este estudiante de Ciencias Políticas:

En lo más terrenal, me gustaría tener mi campito, plantar cositas, tener una casa de campo para ir los fines de semana a descansar. Tener una avioneta. (U1CSPOLI1NTJA02)

Objetivos personales y ánimo de posesión de objetos materiales e inmateriales se ven reflejados en este núcleo discursivo, cristalizando así una idea de completitud a la cual la formación universitaria y la condición de profesional están llamadas a contribuir en primera línea. La racionalidad construida en torno a esos propósitos es de gran coherencia y eso queda de manifiesto en formas argumentativas que integran verbos como «tener» y «conocer», en primer lugar, para luego recurrir a otros tales como «disfrutar» o «descansar». Se reconoce así la lógica del esfuerzo individual y sus posteriores recompensas; recurriendo una vez más a Weber, diríamos que se trata de discursos que integran a menudo una ética de la responsabilidad individual.

No podemos obviar en la caracterización del sujeto pragmático proyectivo la configuración de un imaginario de la libertad, la cual parece perder su cualidad abstracta - y hasta metafísica - a través de la concreción de objetivos personales. El «tener» y el «conocer» constituyen de un modo u otro el 
sustrato material de una libertad que no tiene otra sede posible que no sea el individuo; tal imaginario prescinde de condiciones sociales adicionales, a menos que la sociedad no se yerga como impedimento de esas expectativas y aspiraciones; el hecho de la ausencia de impedimentos, precisamente, puede ser entendido como la expresión de una esperanza de este subtipo.

Finalmente, debemos consignar la aparición algo sorpresiva $-\mathrm{y}$ quizás marginal en su peso específico entre jóvenes estudiantes - de una modalidad de individualismo que no corresponde ni al tipo defensivo ni al gregario. Este podría ser llamado individualismo anómico, el cual admite como principal característica una suerte de indiferencia total con el hecho de haber llegado a la educación superior; se une aquí a la ausencia absoluta de «vocación» por la formación en la que se encuentra inscrito/a, una nula percepción de tiempo futuro, en términos de aspiraciones y esperanzas personales. Se trata casi de una autovictimización que advierte que la condición de estudiante es producto de la voluntad de los padres o, en sentido más general y abstracto, de la sociedad que en su conjunto obligaría a las personas a obtener una cualificación con reconocimiento social:

Veo la universidad como una obligación. Soy el primero de mi familia que llega a la universidad. (U1INGAMB2NTJA19).

Nos parece, en todo caso, que la emergencia de este sujeto individualista anómico podría dar cuenta de un fuerte desencuentro entre cohortes más recientes y todo cuanto se entiende, en una lógica adultocéntrica, la formación de jóvenes en niveles de enseñanza superior, cuestionada esta última en su utilidad social por los propios usuarios potenciales.

\subsection{Perfil Gregario}

Este es un perfil completamente diferente del anterior en su composición más íntima. Aquí, las razones mismas por las cuales se ha elegido una formación universitaria difieren completamente del perfil precedente. Gran parte del capital 
de conocimientos que se logre acumular con motivo de una formación universitaria deberá ser invertido en importantes cambios en la sociedad, con lo cual — desde nuestro punto de vista — se introduce aquí una novedad que tiene consecuencias en la concepción de la política, puesto que esas subjetividades juveniles no operan según criterios ideológicos definidos con antelación. Por el contrario, el trasfondo de dichas transformaciones se corresponde con lo que podríamos entender como una lectura «principista» de la política, en donde predominan a menudo descripciones de campos en los que se debería intervenir y de acciones que deberían ser realizadas en distintos ámbitos. Los subtipos que se presentan a continuación ponen en la superficie esa nueva inteligibilidad.

En todo caso, en cualquiera de estos subtipos de gregarismo - y la opción nuestra por el uso de este sustantivo no es inocente- se exacerba la condición social de nosotros, los seres humanos, asumiendo con ello algo así como la imposibilidad del quiebre con la sociedad y sus males: la pobreza, la injusticia, la exclusión, el racismo, la explotación, etc. Enfrentar esos males es un imperativo ético y moral, aunque el diagnóstico de los mismos difiere según los subtipos que veremos a continuación. Por último, cabe señalar que en el gregarismo juvenil, bajo cualquier modalidad, constatamos la presencia de un imaginario de la libertad traducido en esperanza que se inclina claramente hacia lo social, relativizando con ello, al mismo tiempo, las posibilidades de concreción individual de dicha esperanza, como se observa en este estudiante de Sociología:

Espero, como país, que haya una protección y justicia aceptable porque entendemos que no hay una justicia fidedigna, tampoco para las mujeres. Yo siento que actos de violencia contra las mujeres, violencia de género, se tienen que terminar. Por otro lado, me encantaría que los sistemas básicos mejoraran, que la educación, la salud y las pensiones fueran otra cosa a lo que son hoy. En lo referente al medioambiente, que cuidemos nuestros recursos naturales como país, que haya cuidado hacia las mascotas o los animales. (U2SOCIOL1TJA52). 


\subsubsection{Idealismo psicologista}

El psicologismo apela a resortes internos de los individuos para motivar y/o justificar un mayor alcance de sus propias acciones, es decir, más allá del sujeto mismo que así piensa. Predomina en este subtipo idealista la búsqueda de una mayor empatía con Alter para obtener resultados mucho más amplios, a saber, un mejoramiento interior de las personas como condición sine qua non para el mejoramiento general de la población. La frase que mejor simboliza esta perspectiva de observación es, sin duda: «Los cambios tienen que comenzar con las personas». Revela una especie de ideal de superación espiritual —léase moral, por ejemplo - de cada persona, con efecto en la vida social. Un crecimiento de ese tipo permitiría otorgar un carácter pacífico y solidario a las relaciones interpersonales, en desmedro de otras marcadas por la agresividad y el egoísmo. En otras palabras, todo acontece como si tras acoger la idea según la cual la sociedad no es finalmente otra cosa que un mero conglomerado de individuos, se pudiere deducir el hecho de que la transformación más importante de una sociedad contemporánea no podría tener lugar sin una transformación previa de los individuos.

Una sociedad más empática. Una sociedad que intente ser mejor, igual es utópico pensar en eso. (U2BIOLOGINTJA14).

Reunir esas condiciones que implican un cambio profundo en los seres mismos subordina cualquier alteración en el plano de las estructuras de la sociedad, posponiéndola, e incluso diluyéndola en la utopía de la «conversión» moral de las personas, en primer lugar. El espacio de la acción social está íntimamente condicionado a los contenidos subjetivos de tal mutación, con lo cual se queda en un simple enunciado, siempre a la espera de la «revolución individual». Prevalece aquí una distancia importante e irreductible con los actores y escenarios reales de la política, si bien es cierto se logran percibir a menudo temas y problemas pertenecientes al ámbito del interés general, es decir, de lo político. 


\subsubsection{Idealismo filantrópico}

La filantropía es definida como una demostración tangible de amor al género humano como tal. Por ende, la sociedad, al constituir el espacio de residencia de aquel, se transforma en el objeto principal de atención. Impera en este subtipo de subjetividad juvenil la reivindicación ontológica de un conjunto de atributos positivos considerados como básicos en una visión humanista de la existencia, sin los cuales advierten con preocupación la progresión de una deshumanización de corte materialista inclinada hacia la búsqueda de lucro, sin sensibilidad alguna por temas candentes como, por ejemplo, el medioambiente. Se expresan aquí atributos virtuosos tales como la solidaridad, la utilidad social de lo que se estudia. En síntesis, cómo contribuir desde la profesión futura a un mayor bienestar social. La perspectiva política es aún algo indefinida.

Me gustaría, en primer lugar, salir del país. Otro, tratar de ayudar a la mayor cantidad de gente que pueda, eso es algo que me preocupa, me gustaría ser una persona útil $\mathrm{y}$ no solo conmigo mismo. (U1DERECH1NTJA11).

La política, más exactamente el compromiso con la acción política, es vista acá de manera alejada de las concepciones clásicas o tradicionales de la política, basadas en un compromiso militante con un trasfondo ideológico insoslayable. Ahora esos compromisos tienen una intencionalidad social directa, la acción política busca efectos inmediatos en las poblaciones afectadas por problemas de distinta índole:

Igual me interesa mucho la política, la verdad me gustaría, como un sueño, ser ministro de Ciencias, Tecnología e Innovación, el ministerio que se abrió hace poco acá en Chile. Igual voy a ser científico, así es que voy a tener los requisitos básicos, no sé mucho de política, pero me gusta lo político, sé que va ligado a lo social. (U1GEOLOG2NTJA41).

Ojalá crear una nueva máquina para ayudar a la gente, ese es mi plan de vida. No sé qué, todavía, pero algo novedoso. (U2INGBIO3NTJA31). 
Sin duda, en este tipo de subjetividades, la cuestión de las utopías puede perfectamente alimentarse de sueños cuya viabilidad no es necesariamente objeto de inquietud. Las soluciones planteadas a los problemas - reales o solo presuntos - puestos en relieve por estos jóvenes podrían surgir incluso de la creatividad de ellos mismos, lo que impulsa efectivamente la idea de acción política hacia horizontes utópicos, tal como se veía en el ejemplo anterior y también en el siguiente:

Profesionalmente, mi sueño sería ser un aporte del lado científico a Chile y de conservación de lo que hay. En ese sentido es lo que más anhelo, ser un aporte y mejorar la falencia que hay hoy en día. (U1INGAMB2NTJA19).

Se advierten entonces, de un modo u otro, fuertes inquietudes sociales a través de formas verbales como «poder ayudar», «ser un aporte», etc., que claramente trascienden las expectativas propiamente personales vinculadas al logro de un título profesional universitario. Entendemos por idealismo filantrópico, un acercamiento genérico hacia lo político, sin por ello manejar necesariamente las claves tradicionales de la política. Por consiguiente, insinuamos, a través de esta caracterización, lo que pueden ser ya las matrices subjetivas a partir de las cuales se estructuren algunas de las nuevas formas de vivenciar la política, cuya presencia está puesta de manifiesto en los comportamientos cívicos actuales de los/las ciudadanos/as en Chile.

\subsubsection{Idealismo político}

En un escenario en apariencia mucho más convencional; las subjetividades que alimentan este subtipo son más afines a un pensamiento político no necesariamente cercano a lo tradicional, aunque con esbozos de esquemas de lucha política, atisbos de concepción de tipos de lucha, alguna reflexión política organizacional y de acción. Este perfil integra ideales tales como la dignidad, la justicia social. Incorpora una lectura más resueltamente 
política de la sociedad, con énfasis en temáticas precisas: medioambiente, educación, temas de género, animalismo, etc.; esto parece ser un elemento revelador de una forma también novedosa de concebir la política, sin alusión a sistemas políticos, ideologías y modelos históricos. Aquí, el área de formación en Ciencias Sociales destaca nítidamente entre aquellas que favorecen este tipo de idealismo.

En tal situación, un segmento no menor de jóvenes estudiantes se esfuerza por llevar a cabo sendas lecturas críticas sobre el capitalismo en etapa de globalización avanzada, sobre las condiciones sociales que amparan la pobreza, sobre la injusticia y la exclusión, sobre el retroceso de los bienes comunes, etc. Aquí, la profesión es vista casi espontáneamente a través de los lentes de lo que subentienden como una utilidad social, a la vez que, como herramienta de un cambio juzgado indispensable y urgente.

Poder ayudar, poder aplicar las herramientas que me van a dar en la universidad, poder ser parte de los cambios que existan, ayudar a que esos cambios se den, ser parte de una sociedad más justa, más equitativa. Poder pensar en soluciones buenas, realmente buenas para los problemas. (U2SOCIOL1NTJA50).

Algo que me gustaría lograr sería ser un aporte o poder entregar lo que haya aprendido en la universidad, a la protección o al resguardo de la infancia (...). Claramente una sociedad donde la dignidad y los derechos sociales estén garantizados y sean practicados en todo sentido. En donde las relaciones sociales que tenemos entre los humanos no necesiten de instituciones para estar funcionando o reprimiéndolas. (U2ANTROP2TJA09).

Aunque esta no es necesariamente una construcción subjetiva que se compromete con el quehacer político tradicional, existen buenas razones para suponer que este subtipo retrocede hoy en día con motivo de la pérdida considerable de prestigio de las actividades ligadas a la política, pero tal afirmación $-o$ en su defecto, desmentir esta última—, en términos empíricos, escapa al alcance de esta investigación. Su peso específico tendría relación, de 
cualquier modo, con sendas transformaciones por intervenir en el campo de la política.

\section{Algunas Reflexiones PROPOSITIVAS}

Tratándose de un estudio exploratorio es evidente que no hay espacio aún para extraer lo que podría ser considerado como todo un conjunto de conclusiones gruesas. De manera entonces que hemos optado por la idea de entregar algunas «reflexiones propositivas» que dejan espacio abierto para nuevas preguntas y para otros estudios, considerando que, precisamente por efecto de la pandemia que hoy aqueja a la humanidad, las sociedades conocerán en breve múltiples transformaciones muy importantes que, sin duda, marcarán con ello un antes y un después. Los/las futuros/as profesionales que han sido entrevistados/as ejercerán en ese mundo, con sentido colectivo o individual, tal como hemos intentado demostrar en esta oportunidad.

Desde luego, nos parece que una primera sugerencia consiste en eliminar del vocabulario hasta el más mínimo vestigio de generalización. Ese es el motivo principal para no incluir en un texto único a estudiantes de ambos establecimientos de educación superior; respondiendo a los perfiles y tipos aquí explicitados, los/las estudiantes de un instituto técnico profesional abren, sin embargo, la puerta a otras consideraciones - etarias, entre otras - que desbordan los límites de este artículo. Es hora de constatar la gran heterogeneidad existente en este segmento de población, trascendiendo el tema de la pertenencia a clases o sectores sociales. Y la razón que sustenta tal consideración de lo heterogéneo es simple: «la juventud», definitivamente, no constituye per se una categoría de análisis, sino una simplificación adultocéntrica, con todo cuanto esto implica. Se esconderían de manera errónea un conjunto de diferencias, tal como hemos intentado demostrar, frente a los desafíos planteados por la sociedad a grupos sociales determinados, en una etapa de sus respectivos itinerarios biográficos. 
Hemos puesto de manifiesto la existencia de dos perfiles bastante diferenciados, diríamos ontológicamente, que a su vez derivan en tipos caracterizados por propósitos distintos asignados subjetivamente a sus acciones, por aspiraciones y expectativas que se relacionan con sueños y esperanzas de índole diversa o, por el contrario, se vinculan con objetivos muy pragmáticos. La materialización en la conciencia del ser individual en las subjetividades que hemos sometido a estudio aparece con mucha fuerza.

Un segundo ámbito de reflexión es el de la individualización. Queda en evidencia, a través de buena parte de los discursos, la consolidación de nuevos sujetos marcados por un férreo apego a un Yo que busca abrirse paso en la sociedad, aunque con diferentes objetivos, tal como lo hemos planteado en estas páginas. Es innegable que en la sociedad chilena de estos tiempos la presencia del sujeto individual irrumpe en distintas direcciones, aunque con un mismo afán: ser reconocido y respetado como tal. Se trata de un individuo que reclama ciudadanía plena, con autonomía en sus decisiones, con respeto garantizado a las diferencias de distinto orden, con ejercicio efectivo de derechos individuales (aunque con omisión relativa de deberes, se escuchará decir), etc.

Cada uno de estos perfiles, tipos y subtipos configura, con mayor o menor nitidez, una escala de «valores» subjetivos a partir de un elemento central que sirve de piso enunciativo para toda una estructura arborescente de significaciones. En definitiva, cada uno de aquellos alberga un imaginario radical que, de manera simbólica, no solamente ha adquirido una dimensión social, sino que ha permitido un desarrollo importante en los términos de imaginarios periféricos o secundarios; en cada uno de esos imaginarios se manifiesta también el peso de la heteronomía - o del pensamiento heredado- y frente al cual existen hoy vuelcos importantes que son visibles a través del fenómeno de denuncia del mundo adultocéntrico (Duarte, 2012) y sus consabidos y heteronómicos epistemes (patriarcado, machismo, esquemas de valores burgueses). 
Este fenómeno se hace más evidente a través de las dudas que surgen en las personas que fueron consideradas en este estudio, respecto de la calidad de los aprendizajes recibidos en contexto de enseñanza remota, por efecto de la pandemia o, quienes en el caso del tipo pragmatismo defensivo, manifiestan no saber para qué se estudia, por ejemplo.

Otra serie de interrogantes está asociada al trabajo subjetivo e intersubjetivo aplicado a la construcción del tiempo, en especial referida a una de sus dimensiones reconocibles: el futuro. El sociólogo francés Maffesoli, desde una sociología posmoderna, evocaba la primacía del tiempo presente, en desmedro de otras dimensiones que, como en el caso del futuro, dejan de tener sentido, en un mundo — nos decía- de apariencias, de narcicismo lúdico, de relaciones proxémicas, que resulta del fin de la lógica prometeica que ha tenido un indiscutible peso hegemónico en nuestra Modernidad. La investigación que sustenta lo descrito en estas páginas desmiente una afirmación tan categórica, reinstalando la dimensión «futuro» en el espacio de las subjetividades juveniles, aunque situándola en dos polos, con ese tiempo venidero como lugar de incertidumbre o bien como horizonte de esperanzas. En medio de una pandemia, es difícil pensar en una superación expedita de tales dicotomías: tanto en el perfil individualista — con sus variantes - como en el gregario, y también en sus propias variantes, persisten, de manera fantasmagórica, esas tensiones entre la concreción eventual de esperanzas, de expectativas profesionales, de aspiraciones o sueños personales y la posibilidad de no concreción. No hay espacio disponible para disipar incertidumbres e inquietudes en nuestros días, en condiciones de pandemia, con todas las incógnitas que ella acarrea.

Finalmente, nos parece indispensable cerrar con una reflexión que no pasa por fuera de la ética profesional. Al respecto, puede resultar evidente para muchas personas, y de aquello tenemos plena conciencia, que ir a preguntar a jóvenes acerca del futuro en medio de una pandemia puede parecer una osadía. Sin embargo, todos los seres humanos nos encontramos actualmente en medio de esta 
tormenta global, incluidas las personas que inician estudios de enseñanza superior, para quienes, obviamente, el mundo no ha dejado de girar. Así nos lo hicieron sentir todos/as esos/as jóvenes que respondieron a nuestro requerimiento investigativo y para quienes solo tenemos palabras de agradecimiento.

RECIBIDO: 8 DE JUNIO DE 2021 ACEPTADO: 13 DE SEPTIEMBRE DE 2021

\section{BIBLIOGRAFÍA}

Araujo, K. y Martuccelli, D. (2012). Desafíos comunes. Retratos de la sociedad chilena y sus individuos. Tomo I. Santiago de Chile: LOM Ediciones.

Aravena, A. y Baeza, M. A. (2015). Construcción imaginaria social de la desconfianza y su relación con el descontento en el Chile actual. Cinta de Moebio, Universidad de Chile, 53, 147-157.

Asún, R., Palma, I., Aceituno, R. y DuArte, F. (2021). El impacto emocional de la pandemia en los jóvenes: sociabilidad, conflicto y política. Revista de Sociología, 1(36), 6-24.

BAEZA, M. A. (2020). Enigmas del presente. Entre el neo-salvajismo y el pseudo populismo. Santiago de Chile: RIL Editores.

- (2015). Hacer mundo. Significaciones imaginario-sociales para constituir sociedad. Santiago de Chile: RIL Editores.

. (2003). Imaginarios sociales. Apuntes para la discusión teórica y metodológica. Concepción: Editorial Universidad de Concepción.

Bonilla-Molina, L. y Ortega, N. (2021). Pandemia, vacunación y retorno a clases presenciales en América Latina y el Caribe. En Portal del Centro Internacional de Investigación Otras Voces en Educación, Informe de Coyuntura Global, mayo 2021, 2-20. Disponible en: www.otrasvoceseneducacion.org

Bourdieu, P. (1990). La juventud no es más que una palabra. Sociología y cultura. Ciudad de México: Grijalbo. 
Canales, M., Guajardo, F. y Orellana, V. (2020). La élite del llano: de la promesa a las desilusiones en la trayectoria postsecundaria de los jóvenes de la nueva clase media. Última Década, 28(53), 78-102.

CAnales, M., Opazo, A. y CAMPS, J. P. (2016). «Salir del cuarto». Expectativas juveniles en el Chile de hoy. Última Década, 24(44), 73-108.

CASTORIADIS, C. (2007). La institución imaginaria de la sociedad. Buenos Aires: Tusquets.

Corona, N. A. (2009). La cuestión de la subjetividad. Perspectivas y dimensiones: yo, identidad, persona. Buenos Aires: Pontificia Universidad Católica Argentina.

DuARTE, C. (2012). Sociedades adultocéntricas: sobre sus orígenes y reproducción. Última Década, 36, 99-125.

FLICK, U. (2012). Introducción a la investigación cualitativa. Madrid: Morata.

Lovón, M. y Cisneros, S. (2020). Repercusiones de las clases virtuales en los estudiantes universitarios en el contexto de la cuarentena por COVID-19: El caso de la PUCP. Propósitos y Representaciones, 8 (SPE3), e588. http://dx.doi.org/10.20511/pyr2020.v8nSPE3.588

Margulis, M. (1996). La juventud es más que una palabra. Ensayos sobre cultura y juventud. Buenos Aires: Biblos.

Martuccelli, D. y De Singly, F. (2012). Las sociologías del individuo. Santiago de Chile: LOM Ediciones.

Martín Criado, E. (1998). Producir la juventud. Madrid: Istmo.

Micin, S. y Bagladi, V. (2011). Salud Mental en Estudiantes Universitarios: Incidencia de Psicopatología y Antecedentes de Conducta Suicida en Población que Acude a un Servicio de Salud Estudiantil. Terapia Psicológica, 29(1), 53-64. https://dx.doi.org/10.4067/S071848082011000100006

SANDOVAL, M. (2003). Jóvenes del siglo XXI. Sujetos y actores en una sociedad en cambio. Santiago de Chile: UCSH.

SepúlvedA, L. y VAldebenito, M. J. (2014). ¿Las cosas claras? Aspiraciones de futuro y proyecto educativo laboral de jóvenes estudiantes secundarios. Estudios Pedagógicos, 40(1), 243-261.

TORRES, L. (2019). Educación, alteridad e imaginarios. Imaginación o Barbarie, $19,66-75$.

Touraine, A. (2016). El fin de las sociedades. Ciudad de México: Fondo de Cultura Económica.

UNIVERSIDAD DE CHILE (2021). Vida en pandemia: para un aprendizaje social de impactos y respuestas a la Crisis en la vida cotidiana. Estudio longitudinal 
sobre la vida cotidiana en la crisis del covid-19. Primeros resultados. Informe 1b. Julio a diciembre de 2020. Santiago, Chile. Disponible en: https://www.uchile.cl/noticias/166860/sectores-pobres-jovenes-ymujeres-los-mas-golpeados-por-la-pandemia

ZARZURI, R. y GANTER, R. (2005). Jóvenes: la diferencia como consigna. Ensayos sobre la diversidad cultural. Santiago de Chile: CESC. 